\title{
Measurements of Surface and Near-surface Residual Stress in 4330 Low Alloy Carbon Steel Weld Clad Components
}

\author{
G. Benghalia ${ }^{1, a}$, S. Rahimi ${ }^{1, b}$ and J. Wood ${ }^{2, c}$ \\ ${ }^{1}$ Advanced Forming Research Centre (AFRC), University of Strathclyde, Glasgow, UK \\ ${ }^{2}$ Deparment of Mechanical and Aerospace Engineering, University of Strathclyde, Glasgow, UK \\ agladys.benghalia@strath.ac.uk, bsalah.rahimi@strath.ac.uk, cj.wood@strath.ac.uk
}

\begin{abstract}
Keywords: Residual Stress, X-Ray Diffraction (XRD), Electronic Speckle Pattern Interferometry (ESPI), Incremental Centre Hole-drilling, Finite Element Modelling, Weld Cladding
\end{abstract}

\begin{abstract}
Weld cladding of low alloy carbon steel generates compressive residual stress in the clad layer, in turn potentially improving resistance to fatigue failure, depending on the material used for cladding. The current paper summarises the results of investigations on the magnitude and distribution of residual stress in these weld clad components, undertaken using different techniques including X-ray diffraction, and incremental centre hole drilling based on both strain gauge rosettes and electronic speckle pattern interferometry. Results confirm the presence of tensile residual stress when cladding with Inconel 625 beyond the initial clad profile and compressive residual stress when cladding with 17-4 PH steel. The complementary nature of XRD and hole drilling techniques is highlighted with considerations regarding the weld clad profile and stress distribution with depth. Modelling of residual stress induced by weld cladding using a thermal transient analysis is presented. Simplification of the weld cladding process is shown to provide good correlation with experimentally measured residual stress. Complexities in modelling material behaviour and hence accurate prediction of residual stress are discussed. Chemical composition of the weld into the heat-affected zone and substrate is presented for both weld clad materials, highlighting the effects of alloying and diffusion on chemical composition. Given the complexities in obtaining accurate thermo-mechanical material properties required for modelling, and that residual stress profiles are measured to a limited depth into the clad layer, recommendations are made for the continuation of both experimental and simulation studies.
\end{abstract}

\section{Introduction}

Residual stresses present in a component post-manufacture prior to loading, are of crucial importance to ensure accurate determination of the performance of a component in service. Such stresses are described as arising due to misfits between regions, different parts or different phases [1]. Unprocessed raw materials will invariably contain residual stresses, with manufacturing processes acting as additional sources of residual stress resulting in alteration of the distribution and status of residual stress. The understanding of these elastic, self-equilibrating stresses requires knowledge of the processes experienced by the component (e.g. heat treatment, mechanical work or joining), and the extent to which these processes alter the residual stress magnitude and distribution.

Residual stresses can be categorised as macro and micro residual stresses. Macro stresses are those that are present at scales comparable to the size of the component, also known as Type I residual stress, whilst micro stresses are in the scale of several grains (Type II) and atomic scales (Type III) [2]. These stresses arising due to elastic strain energy in the lattice structure of a material can act as a driving force for crack initiation and accelerate crack propagation. It is commonly known that the presence of tensile residual stresses negatively impacts fatigue life, whilst the presence of compressive residual stresses are beneficial for fatigue life. The presence of a compressive residual stress is therefore particularly beneficial at the surface of a component where operational stresses are 
often highest. Upon superpositioning of the residual stresses with cyclic operational stresses, the entire stress cycle would ideally remain in the compressive region, resulting in retardation of crack propagation. Crack initiation is however thought to be uninfluenced by the presence of compressive residual stresses [3]. Compressive residual stresses can improve corrosion performance and resistance to stress corrosion cracking in critical environments [4]-[6]. In this study, residual stresses induced by weld cladding, using different clad materials, are investigated. A cylinder of 4330 low alloy carbon steel is weld clad with nickel-chromium-based superalloy Inconel 625 and 17-4 precipitation hardening martensitic stainless steel. The weld cladding process, due to the joining of dissimilar materials, involves thermo-mechanical and chemical mechanisms that give rise to the generation of residual stresses with complex distribution. A shrinkfit effect occurs due to the effective shrinking of the cladding relative to the substrate. Constraint on thermal expansion and contraction is produced through the heating and cooling cycle during welding. Volume changes due to phase transformation, precipitation or chemical reactions can result in chemically induced residual stresses. The deposition process and subsequent cooling of the clad component can be controlled to modify residual stresses depending on the spatial and temporal variation of the process [7], [8]. Furthermore the original material properties and microstructures are altered during the joining of materials through the effects of alloying and diffusion [9]. On a microscopic level, varying values of thermal properties in constituent phases can also generate thermally induced residual stresses [10].

Herein the residual stress distribution in near-surface regions of the weld clad components are investigated using several measurement techniques. The determination of residual stresses can be achieved through means of relaxation or diffraction [11]. In this study residual stress measurements have been carried out based on both principals using X-Ray diffraction (XRD) and hole drilling. The generation of residual stress due to weld cladding has also been modelled using a thermal transient analysis.

\section{Weld Cladding Process}

Weld overlay cladding of hollow cylinders, made from 4330 low alloy carbon, was achieved using hot-wire Gas Tungsten Arc Welding (GTAW) to deposit a layer of clad material onto the outer diameter of the cylinders to create a bond between the two materials. Two cladding materials, Inconel 625 and 17-4 PH, were used on two different cylinders. For each sample, a two-pass deposition process was utilised resulting in a total clad layer thickness of $6 \mathrm{~mm}$, with cylinder dimensions noted in Fig. 1(a).

\section{Residual Stress Measurements}

X-Ray Diffraction. Surface residual stress measurements were obtained by XRD using a PROTO-LXRD diffractometer and $\sin ^{2} \psi$ method according to the NPL good practice guide [12], [13]. The stresses were calculated from the strains of the $\{311\}$ and $\{211\}$ Bragg reflections at $155.2^{\circ}$ and $155.1^{\circ}$ Bragg angles, considering elastic Young's modulus of $168 \mathrm{GPa}$ and $184 \mathrm{GPa}$ and Poisson's ratios of 0.29 and 0.272 for Inconel 625 and 17-4 steel, respectively. Weld bead peaks were utilized as measurement points, with a path assigned from the reference face spanning 20 peaks. Measurements were obtained in perpendicular axial $\left(\varphi=0^{\circ}\right)$ and hoop $\left(\varphi=90^{\circ}\right)$ directions as illustrated in Fig. 1(a).

Hole-drilling using optical technique. The StressTech Prism system was used in the measurement of residual stresses using hole drilling based on electronic speckle pattern interferometry (ESPI) [14]. The sole requirement regarding surface preparation is a clean surface with low reflectivity, the clad cylinder therefore ideal. Drill diameters determine the depth to which measurements can be obtained, residual stresses obtained to a depth of $1.2 \mathrm{~mm}$.

Hole-drilling using strain gauge rosettes. The incremental centre hole drilling (ICHD) method, accurately obtaining measurements to a depth of approximately half of the drill diameter [15], was also undertaken using the SINT Technology MTS3000 system to obtain residual stress distributions. Strain gauge installation in diametrically opposing locations required machining of an average of 306 $\mu \mathrm{m}$ and $586 \mu \mathrm{m}$ for Inconel 625 and 17-4 PH clad profiles respectively. 

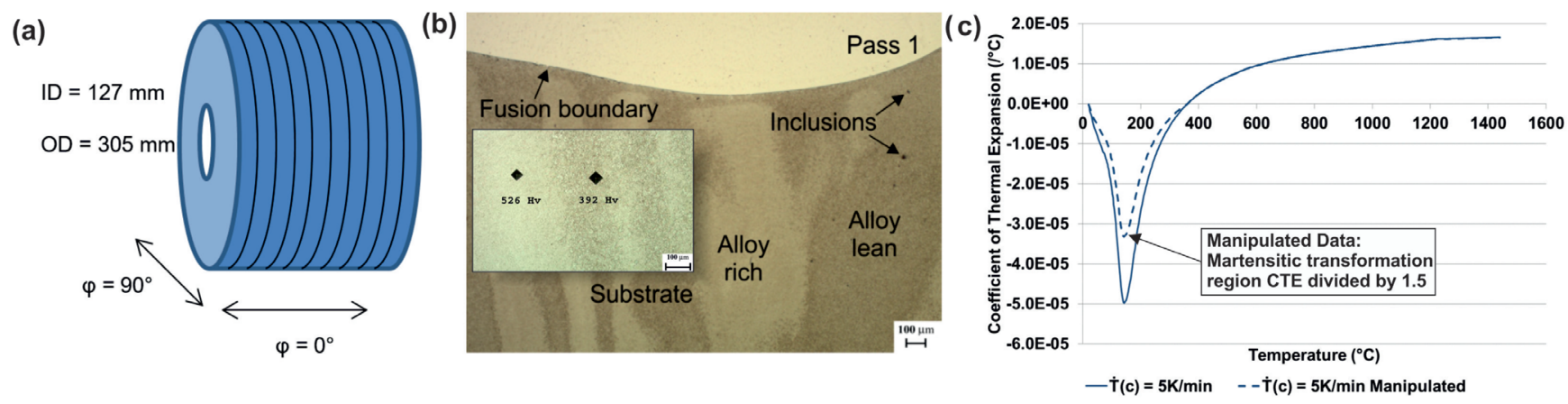

Fig. 1. (a) Orientation of the sample for XRD stress measurements (i.e. $\varphi$-angles) (b) fusion boundary of Inconel 625 clad - magnification factor x50 (c) manipulation of 17-4 PH coefficient of thermal expansion (CTE).

\section{Simulation of the Weld Cladding Process}

A 2D axisymmetric model was utilised for the simulation of the weld cladding process, assuming weld passes to be deposited on the entire outer diameter at one time step. The thermal transient analysis consisted of heating the pipe to a temperature of $300^{\circ} \mathrm{C}$ prior to application of the weld material at melt temperature. The entire component was then slowly cooled using a convective heat transfer coefficient of $\mathrm{h}=10 \mathrm{~W} / \mathrm{m}^{2} \mathrm{~K}$, with latent heat effects neglected and radial edges insulated to simulate no axial heat transfer. An elastic-perfectly plastic material was assumed utilizing experimentally obtained thermal and mechanical properties for clad and heat-affected zone (HAZ) regions. Fig. 1(b) shows the fusion boundary and heavy micro-segregation in the HAZ of the Inconel 625 clad.

\section{Results}

X-Ray Diffraction. Fig. 2 indicates the presence of primarily compressive residual stress on the Inconel 625 weld clad profile in both axial and hoop directions, with a maximum generally around $300 \mathrm{MPa}$. It can also be seen that a number of points illustrate the presence of tensile residual stress, although those close to a zero value possess error bars in the region that would suggest these may also be low compressive stresses. Hoop stresses shown in Fig. 2(b) appear to be tensile towards the reference edge of the cylinder, however this is not observed for axial stresses. Given the nature of the weld clad profile, insufficient diffraction may arise should the beam extend across more than one weld bead and this will be observed as a variation in stress values. Furthermore geometrical variations, surface irregularities and sampling population can give rise to variations. It should also be noted that strain values are averaged in the measurement region and this is reflected ultimately in stress values.

Residual stress measured in the 17-4 PH clad surface showed compressive residual stress at the majority of measurement locations, slightly less compressive than in the case of Inconel 625. In the axial stress component a small number of points indicated low tensile residual stress, Fig. 3(a), however the hoop stress component highlighted that all residual stresses measured were compressive, Fig. 3(b).

Calculated error values are also generally smaller in the case of the 17-4 PH clad cylinder, likely due to the increased sampling population in the martensitic microstructure.

Hole drilling techniques and comparisons with FE model. The hole drilling methods utilized obtain residual stresses in the near surface region, serving as a means for comparison with the simulation model. Fig. 4 and Fig. 5 compare residual stress components obtained through simulation and experimental methods. In the case of the Inconel 625 clad layer good correlation can be seen between the simulation and ICHD residual stress for both stress components. In the case of ESPI, compressive residual stress is observed in both stress components at the surface, to a similar level as was observed in XRD measurements. ICHD A and B represent two measurements at diametrically 
opposed locations on the same component, undertaken for the purposes of repeatability, while average XRD values are plotted.
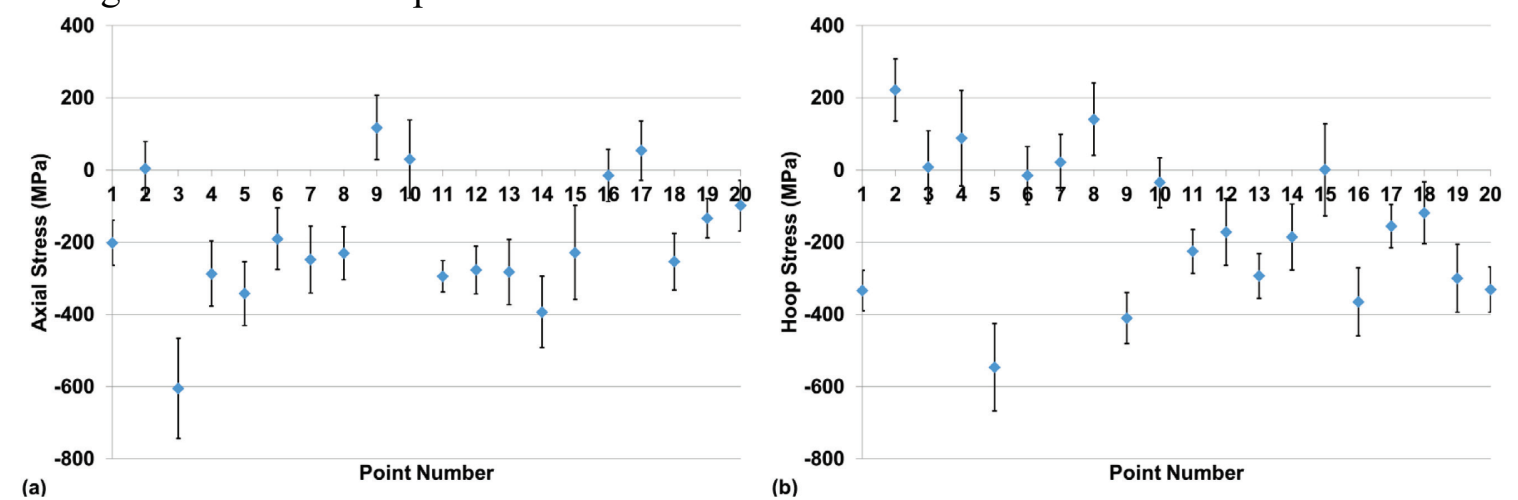

Fig. 2. (a) Axial stress and (b) hoop stress measured in Inconel 625 as-clad surface measurements obtained on 20 consecutive weld bead peaks using XRD.
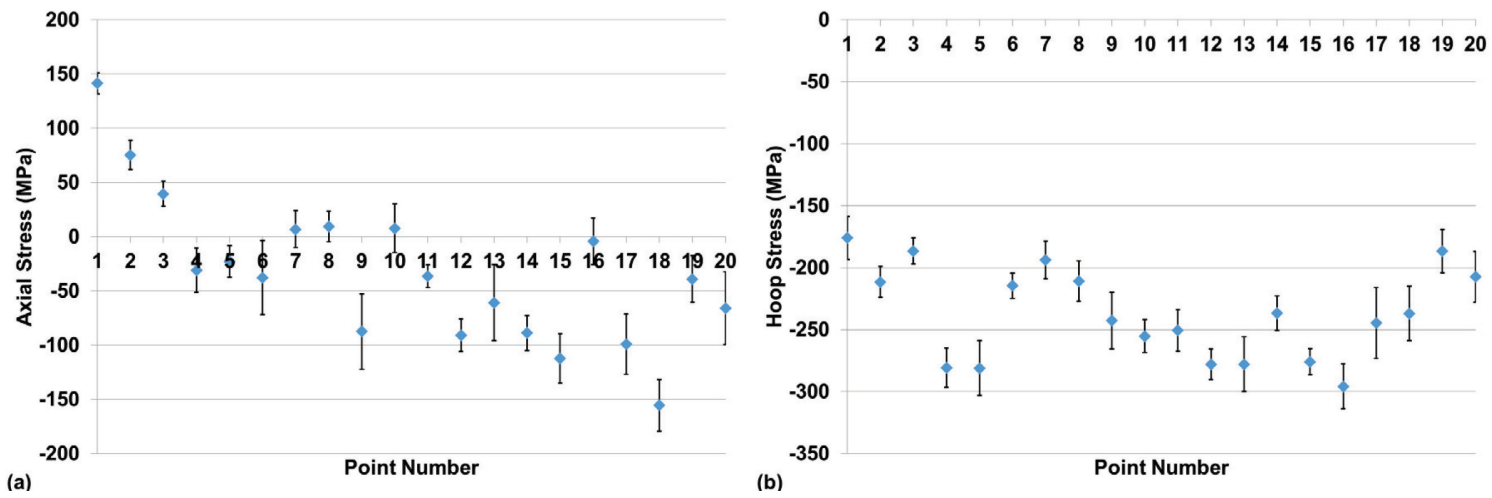

Point Number

(b)

Fig. 3. (a) Axial stress and (b) hoop stress measured in 17-4 PH as-clad surface - measurements obtained on 20 consecutive weld bead peaks using XRD.

Towards the greatest depth $(\approx 1.2 \mathrm{~mm})$ of the ESPI measurement it can be seen that the residual stress levels matches more closely with those obtained in the simulation.

Comparing experiment and simulation for a 17-4 PH clad, shows that in the case of axial stress good correlation is achieved for hole drilling methods with the simulation (Fig. 5(a)). Hoop stresses show that ESPI values are almost zero at the surface, increasing in compression towards a depth of $1.2 \mathrm{~mm}$, while ICHD values match closely with simulation.

\section{Discussion}

As highlighted, correlation between XRD and ESPI methods was seen to be good at the component surface. The complementary nature of XRD and ESPI hole drilling has therefore been demonstrated herein, along with the inability of the simulation model to capture stress variation at the surface due to the weld clad profile. In terms of residual stress measurement, techniques providing bulk residual stress, such as the contour method [16] and deep-hole drilling [17], would allow increased understanding of residual stresses throughout the clad cylinder, as opposed to near-surface stresses presented in this study.

Considerations on weld geometry. In the Inconel 625 clad cylinder both XRD and ESPI hole drilling measurements indicated compressive surface residual stresses, however residual stress in the clad layer measured by ICHD is tensile and in agreement with simulation results. This may be due to (i) the weld bead geometry influencing the residual stress measured by both XRD and ESPI hole drilling, or (ii) the FE simulation not being able to predict the real process and in turn levels of residual stress. It is expected that results obtained by ICHD do not match surface results of ESPI hole drilling and XRD, as the surface residual stress profile is changed by surface preparation for strain gauge installation. 
Material behaviour. In Fig. 5, simulation results are presented for two cases: original and manipulated. In the manipulated case (simulation B), experimental data obtained for coefficient of thermal expansion (CTE) was manipulated as shown in Fig. 1(c) to account for the rapid cooling rate during the welding process. Studies have been conducted into dilatation during a cooling rate of 234 $\mathrm{K} / \mathrm{s}$ [18], however this level of cooling could not be obtained experimentally. Increased accuracy in experimental data is required to account for CTE variation, particularly during the martensitic transformation to ensure that accurate material behavior is modelled.
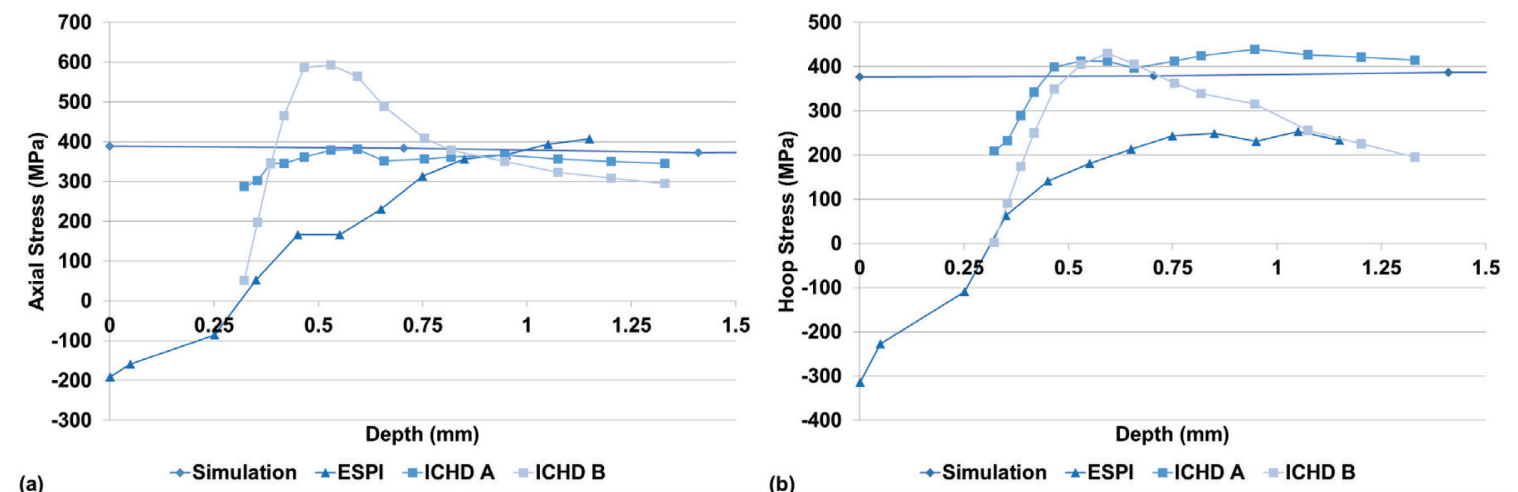

(a)

$\rightarrow$ Simulation $₫$-ESPI - -ICHD A -ICHD B

(b)

Fig. 4. Comparing simulation and experimental (a) axial and (b) hoop residual stress in the Inconel 625 clad layer.
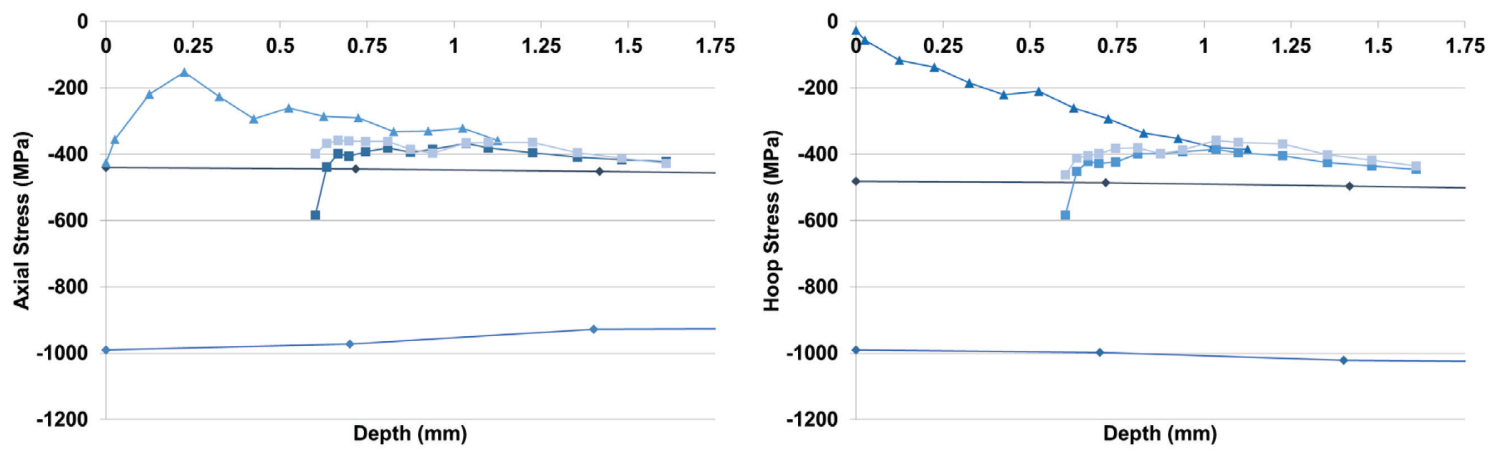

(a) $\rightarrow$ Simulation $\rightarrow$ Simulation manipulated $\rightarrow$ ESPI $\rightarrow$ ICHD A $\rightarrow$ ICHD B

(b) $\rightarrow$ Simulation $\rightarrow$ Simulation manipulated $₫ \mathrm{ESPI}-\mathrm{ICHD} A-\mathrm{ICHD}$ B

Fig. 5. Comparing simulation and experimental (a) axial and (b) hoop residual stress in the 17-4 PH clad layer.

Alloying and diffusion. Fig. 1(b) highlighted heavy HAZ micro-segregation, chemical analysis of these regions indicating diffusion from the clad layer into the substrate. Higher chromium and nickel levels were present in alloy rich regions increasing hardness values as shown. Furthermore chemical analysis of clad passes illustrated higher iron levels in the first Inconel 625 pass, diffused from the 4330 substrate. Similarly substrate diffusion increased iron levels in the first 17-4 PH clad pass. These factors will impact material properties and resulting residual stresses. Care must be taken to ensure that crack susceptibility and tensile residual stresses do not result from the weld cladding process. Microstructural modelling would enable greater control of residual stress generation during weld cladding.

\section{Conclusions}

Weld cladding of a 4330 cylinder was achieved using a hot-wire GTAW process using Inconel 625 and 17-4 PH as clad materials. The major observations of this work are concluded as follows:

- The residual stresses throughout the component were measured using XRD and two hole drilling techniques, one based on electronic speckle pattern interferometry (ESPI) and the other based on strain gauge rosettes. These methods are shown to be complementary.

- Good correlation was obtained between experiment and simulation upon manipulation of CTE values for 17-4 PH to account for high cooling rates during welding. 
- XRD and ESPI hole drilling results indicated that weld bead geometry influenced surface measurements, with stresses near-surface transforming from compressive to tensile for an Inconel 625 clad.

- Discrepancies in the results of different residual stress measurements techniques have been highlighted. The study indicates the need for a range of residual stress measurement techniques to gain knowledge of the residual stress distribution throughout the component.

- Weld cladding with Inconel 625 resulted in the presence of tensile residual stresses in the clad layer beyond the initial weld bead profile, while compressive residual stresses were observed in the 17-4 PH clad layer.

\section{References}

[1] P. J. Withers and H. K. D. H. Bhadeshia, "Residual Stress: Part 2 - Nature and Origins," Mater. Sci. Technol., vol. 17, no. April, pp. 366-375, 2001. http://dx.doi.org/10.1179/026708301101510087

[2] F. A. Kandil, J. D. Lord, A. T. Fry, and P. V. Grant, "A Review of Residual Stress Measurement Methods A Guide to Technique Selection,” Teddington, 2001.

[3] L. Wagner, "Mechanical Surface Treatments on Titanium, Aluminum and Magnesium Alloys," Mater. Sci. Eng. A, vol. 263, pp. 210-216, 1999. http://dx.doi.org/10.1016/S0921-5093(98)01168-X

[4] A. F. Liu, Mechanics and Mechanisms of Fracture: An Introduction. Ohio, USA: ASM International, 2005.

[5] S. Rahimi, K. Mehrez, and T. J. Marrow, "Effect of surface machining on intergranular stress corrosion cracking (IGSCC) in sensitised type 304 austenitic stainless steel," Corros. Eng. Sci. Technol., 2016. http://dx.doi.org/10.1080/1478422X.2015.1122295

[6] S. Rahimi and T. J. Marrow, "Effects of orientation, stress and exposure time on short intergranular stress corrosion crack behaviour in sensitised type 304 austenitic stainless steel," Fatigue Fract. Eng. Mater. Struct., vol. 35, pp. 359-373, 2011. http://dx.doi.org/10.1111/j.1460-2695.2011.01627.x

[7] G. Schnier, J. Wood, and A. Galloway, "An Experimental Validation of Residual Stresses in Weld Clad Pipelines," in Research and Applications in Structural Engineering, Mechanics \& Computation:

Proceedings of the Fifth International Conference on Structural Engineering, Mechanics \& Computation, 2013, pp. 613-617. http://dx.doi.org/10.1201/b15963-113

[8] G. Schnier, J. Wood, and A. Galloway, "Investigating the Effects of Process Variables on the Residual Stresses of Weld and Laser Cladding," Adv. Mater. Res., vol. 996, pp. 481-487, Aug. 2014. http://dx.doi.org/10.4028/www.scientific.net/amr.996.481

[9] G. Benghalia and J. Wood, “Autofrettage of Weld Clad Components,” Procedia Eng., vol. 130, pp. 453465, 2015. http://dx.doi.org/10.1016/j.proeng.2015.12.239

[10] G. Benghalia and J. Wood, "Material and residual stress considerations associated with the autofrettage of weld clad components," Int. J. Press. Vessel. Pip., vol. 139-140, pp. 146-158, 2016. http://dx.doi.org/10.1016/j.ijpvp.2016.02.003

[11] P. J. Withers and H. K. D. H. Bhadeshia, "Residual Stress: Part 1 - Measurement Techniques," Mater. Sci. Technol., vol. 17, no. April, pp. 355-365, 2001. http://dx.doi.org/10.1179/026708301101509980

[12] M. E. Fitzpatrick, A. T. Fry, P. Holdway, F. A. Kandil, J. Shackleton, and L. Suominen, "Measurement Good Practice Guide No. 52: Determination of Residual Stresses by X-Ray Diffraction - Issue 2," Teddington, UK, 2005.

[13] ASTM International, Standard Test Method for Residual Stress Measurement by X-Ray Diffraction for Bearing Steels. West Conshohocken, PA, USA, 2012.

[14] R. Jones and J. A. Leendertz, "Elastic constant and strain measurements using a three beam speckle pattern interferometer,” J. Phys. E Specif. Instruments, vol. 7, pp. 653-657, 1974.

[15] P. V. Grant, J. D. Lord, and P. S. Whitehead, "Measurement Good Practice Guide No. 53 - Issue 2: The Measurement of Residual Stresses by the Incremental Hole Drilling Technique," Teddington, UK, 2006.

[16] M. B. Prime, "Cross-sectional mapping of residual stresses by measuring the surface contour after a cut," $J$. Eng. Mater. Technol., vol. 123, pp. 162-168, 2001. http://dx.doi.org/10.1115/1.1345526

[17] R. H. Leggatt, D. J. Smith, S. D. Smith, and F. Faure, "Development and experimental validation of the deep hole method for residual stress measurement," J. Strain Anal., vol. 31, no. 3, 1996. http://dx.doi.org/10.1243/03093247V313177

[18] L.-E. Lindgren, Computational Welding Mechanics: Thermomechanical and Microstructural Simulations. Cambridge, UK: Woodhead Publishing Limited, 2007. 